\title{
Composite crash absorber for aircraft fuselage applications
}

\author{
S. Heimbs ${ }^{1}$, F. Strobl ${ }^{1}$, P. Middendorf ${ }^{1}$ \& J. M. Guimard ${ }^{2}$ \\ ${ }^{1}$ EADS Innovation Works, Munich, Germany \\ ${ }^{2}$ EADS Innovation Works, Suresnes Cedex, France
}

\begin{abstract}
A composite crash absorber element for potential use in z-struts of commercial aircraft fuselage structures was developed, which absorbs energy under crash loads by cutting the composite strut into stripes and crushing the material under bending. The design concept of this absorber element is described and the performance is evaluated experimentally in static, crash and fatigue test series on component and structural level under normal and oblique impact conditions. The physics of the energy absorption by high rate material fragmentation and delamination interactions are explained and numerical modelling methods in explicit finite element codes for the simulation of the crash absorber are assessed. Keywords: composite crash absorber, z-strut, aircraft crashworthiness, energy absorption, crushing, fragmentation, delamination, finite element simulation.
\end{abstract}

\section{Introduction}

Modern commercial aircraft are designed for crashworthiness with the fuselage structure's crash behaviour typically being evaluated in vertical drop tests, as illustrated in Fig. 1 [1-3]. In case of metallic materials, the energy is normally absorbed by plastic deformation, while it is crushing and fracture for composite structures. Besides the deformation of the primary structure itself, additional energy absorbers can be incorporated to improve the crash behaviour, which can be based on different concepts. In the chain of energy absorption, the subfloor area of the lower fuselage is loaded first. A lot of research was conducted with respect to composite sine wave beams in the subfloor structure that are crushed under vertical crash loads [4-9]. Further concepts are based on foam [10] or honeycomb absorbers $[11,12]$ in the subfloor structure. 


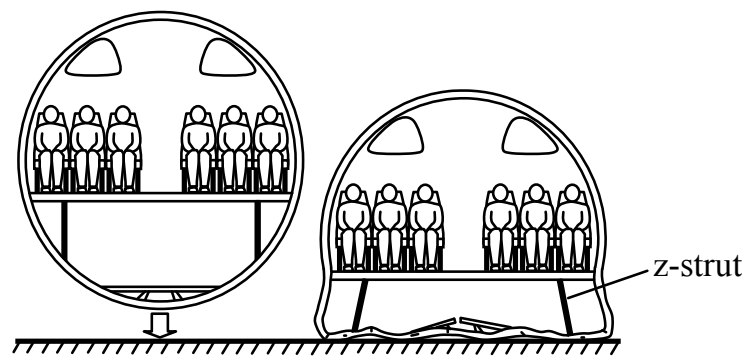

Figure 1: Illustration of aircraft fuselage drop test for crashworthiness evaluation.

A new approach, presented in this paper, includes energy absorbers in the zstruts of the fuselage (Fig. 1) [13]. Z-struts are the connection of passenger floor and lower frames, acting as the support in vertical (z-) direction. In the crash case, they are loaded in axial compression as soon as the lower fuselage part is flattened. In this study, a lightweight composite crash absorber element was developed, which absorbs energy under compression loads and meets at the same time design criteria like stiffness, buckling stability, trigger load or fatigue performance. Besides the design and experimental testing of this absorber device, this paper addresses the fundamentals of composite fragmentation and approaches for numerical modelling.

\section{Crash absorber element}

When it comes to the weight-specific energy absorption (SEA) of crash elements, that are also found in automotive or train applications, it is known that composite materials are superior compared to metallic absorbers. The fragmentation of fibrereinforced composites happens under a nearly ideal constant crush load level, while the folding pattern of metallic crash boxes under compression typically leads to severe load amplitudes for each fold [14]. The characteristics of composite crash absorbers and the influence of various geometrical shapes, fibre architectures or trigger mechanisms have been investigated extensively in the past [15-19].

The idea behind the following study was to use the z-strut - made from a circular profile of composite material - as the crash element that is being crushed in its supporting device, allowing for a very long energy absorption length, basically the whole length of the z-strut (Fig. 2). The absorber element and its components are shown in detail in Fig. 3, their materials and functions are explained as follows:

\section{Composite strut:}

The composite strut is made from a carbon fibre/epoxy prepreg laminate with $50 \%$ fibres in $0^{\circ}$ (axial) and $\pm 45^{\circ}$ direction, which was most suitable for current crush load requirements. Of course, the lay-up can be adjusted for other requirements. Although braided struts were also tested, prepreg material led to higher reproducibility. To avoid corrosion problems with the aluminium supports, an outside layer of glass fibres was used. 


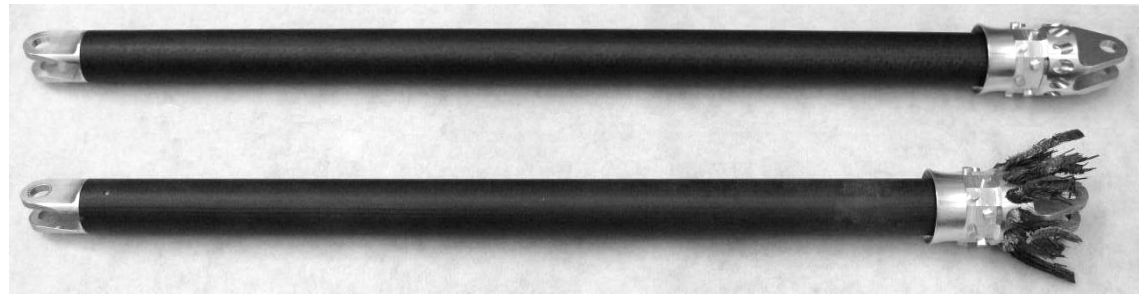

Figure 2: Composite z-strut with integrated energy absorber (before/after crash test).

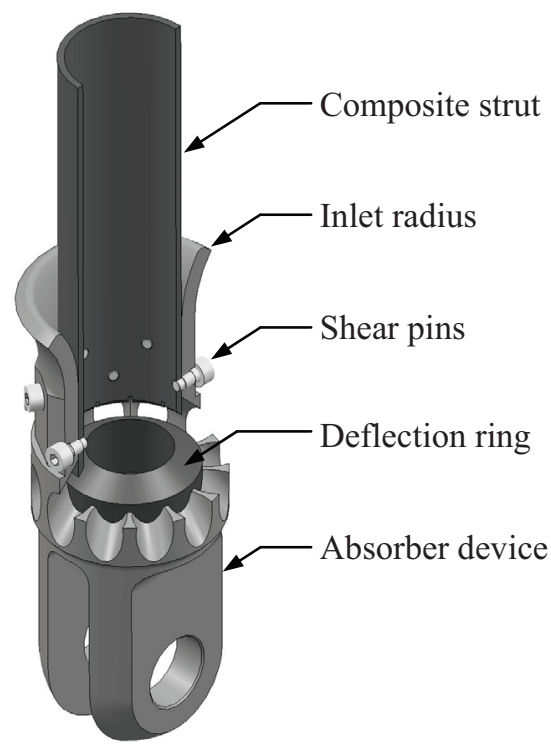

Figure 3: Energy absorber device and components.

\section{Inlet radius:}

The inlet radius at the upper end of the support device ensures the functionality under oblique impact conditions up to an angle of about $10^{\circ}$.

\section{Shear pins:}

All static loads are transferred from the composite strut to the metallic absorber device through shear pins (Fig. 4a). In case of the crash load, they are supposed to fail at a specific limit by shear failure, so that the crushing of the composite strut begins. Titanium pins were found to be superior compared to aluminium pins, as their yield and ultimate strength values are closer, leading to a more brittle failure without undesired nonlinearities. Composite CF/PEEK pins were also tested as an alternative but showed no improvement. Since solid pins led to bearing failure of the composite laminate, hollow titanium pins were used. The final geometry of the pins and their fillet radii were optimised with respect to fatigue demands. 


\section{Deflection ring:}

The 7075-T651 aluminium inner ring inside the absorber element acts as a deflection device. Once the shear pins fail, the composite strut hits the inner ring and the composite material is deflected outwards. The angle of this deflection device primarily influences the crush load of the whole absorber system.

\section{Absorber device:}

The aluminium absorber device is basically the support for the z-strut and the connection to the fuselage structure. It consists of several circumferential holes, through which the composite z-strut is pushed after being deflected by the inner ring. Due to the sharp edges of the holes, the strut is cut into stripes. Through these holes the outflow of the material is ensured so that no blockage can occur, assuring the absorber functionality. Some trials were also performed with titanium absorber devices, leading to a slightly lower SEA, which may be attributed to the higher wear resistance and hence sharper cutting edges. The total weight of $765 \mathrm{~g}$ of this conceptual z-strut is lower than the weight of a state-of-the-art aluminium z-strut.

In summary, the energy is absorbed by cutting the z-strut into stripes and bending the material outward via the deflection device. During this process it delaminates and is crushed and fragmented to a large extent (Fig. 4b). For this application, this process turned out to be the optimum to meet the targeted crush load level, which is illustrated in Fig. 5. The first peak in the force-displacement diagram is the trigger load, when the shear pins fail and the absorber starts to work. It was specified to be $20 \%$ higher than the ultimate load of the static design and is therefore only reached in the crash case. After shear failure of the pins, the load level drops to zero, due to free displacement of the composite tube up to contact with the deflection ring, which is supposed to avoid the addition with the following peak load when the crushing begins. After this second peak a stable crush load plateau develops that lasts until all energy is absorbed.

For sure, the crush load level can be increased by crushing the whole tube instead of cutting it into stripes, but if the SEA increases the wall thickness of the tube would have to be reduced to meet the targeted load level, leading to buckling and bearing failure issues. Also the continuous material outflow would be more problematic and the initial peak load is much higher for the full tube crushing.

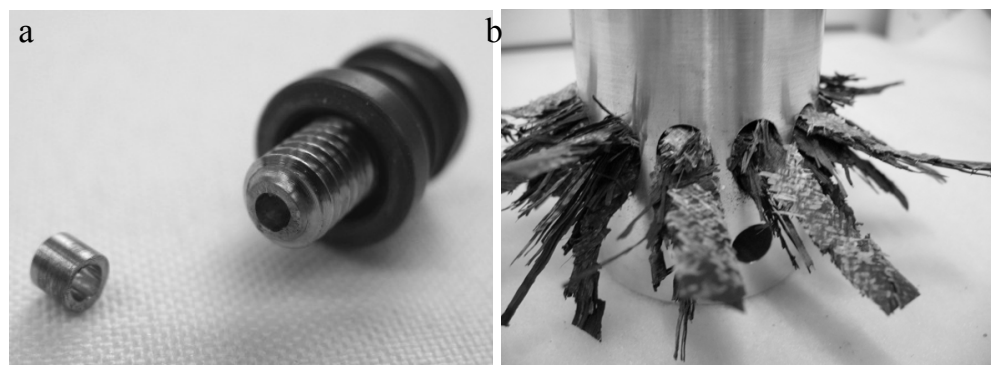

Figure 4: $\quad$ Shear pin failure (a) and failed material (b). 


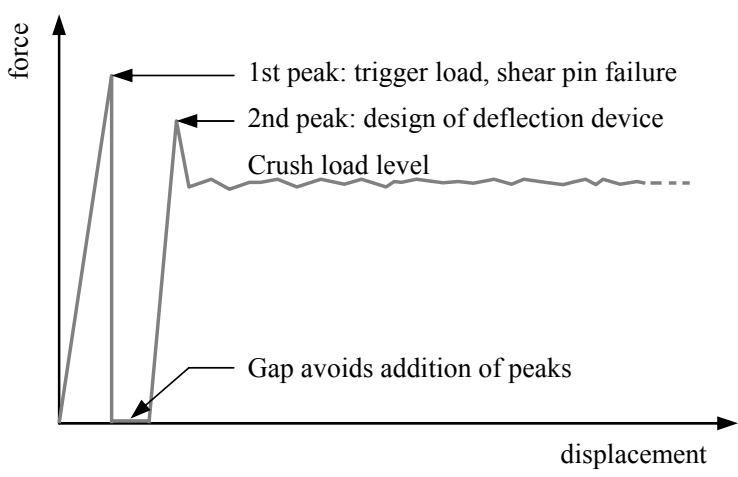

Figure 5: Absorber characteristics in force-displacement diagram.

The development of this crash absorber is based on a step by step testing pyramidal approach: starting with cylinder crush tests to identify the SEA of various laminates and materials, over static absorber tests to evaluate the shear pin failure, up to crash tests of absorber components and finally full scale crash tests of complete z-struts (Figs. 6 and 7). These latter tests were performed successfully both under normal and oblique impact conditions at the Institute of Composite Materials (IVW), Kaiserslautern. It is important to ensure that the absorber also works in the oblique configuration, as there is some rotation of the struts to be expected in the crash load case of the fuselage (see Fig. 1). The shear pin failure was proven not to be influenced by strain rate, which could be concluded from static and dynamic tests. The testing spectrum was finalised by fatigue tests under tension-compression loads. The main conclusion from this test spectrum was the robustness of the absorber design. While other absorber concepts often show their full performance only under a narrow range of ideal conditions, this system worked under various conditions and angles with an impressively high reproducibility.

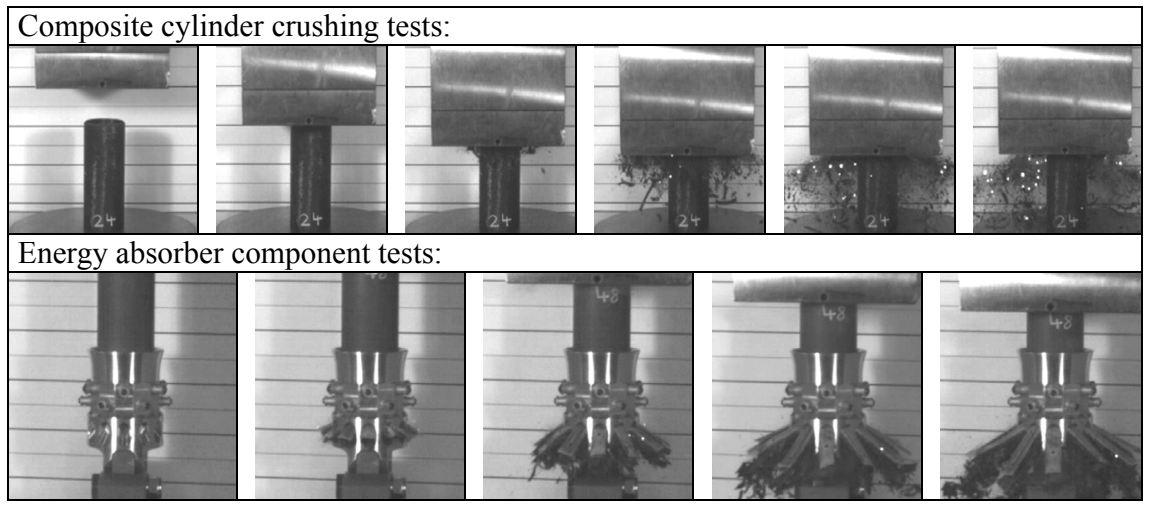

Figure 6: Extract of crash absorber test spectrum: component tests. 


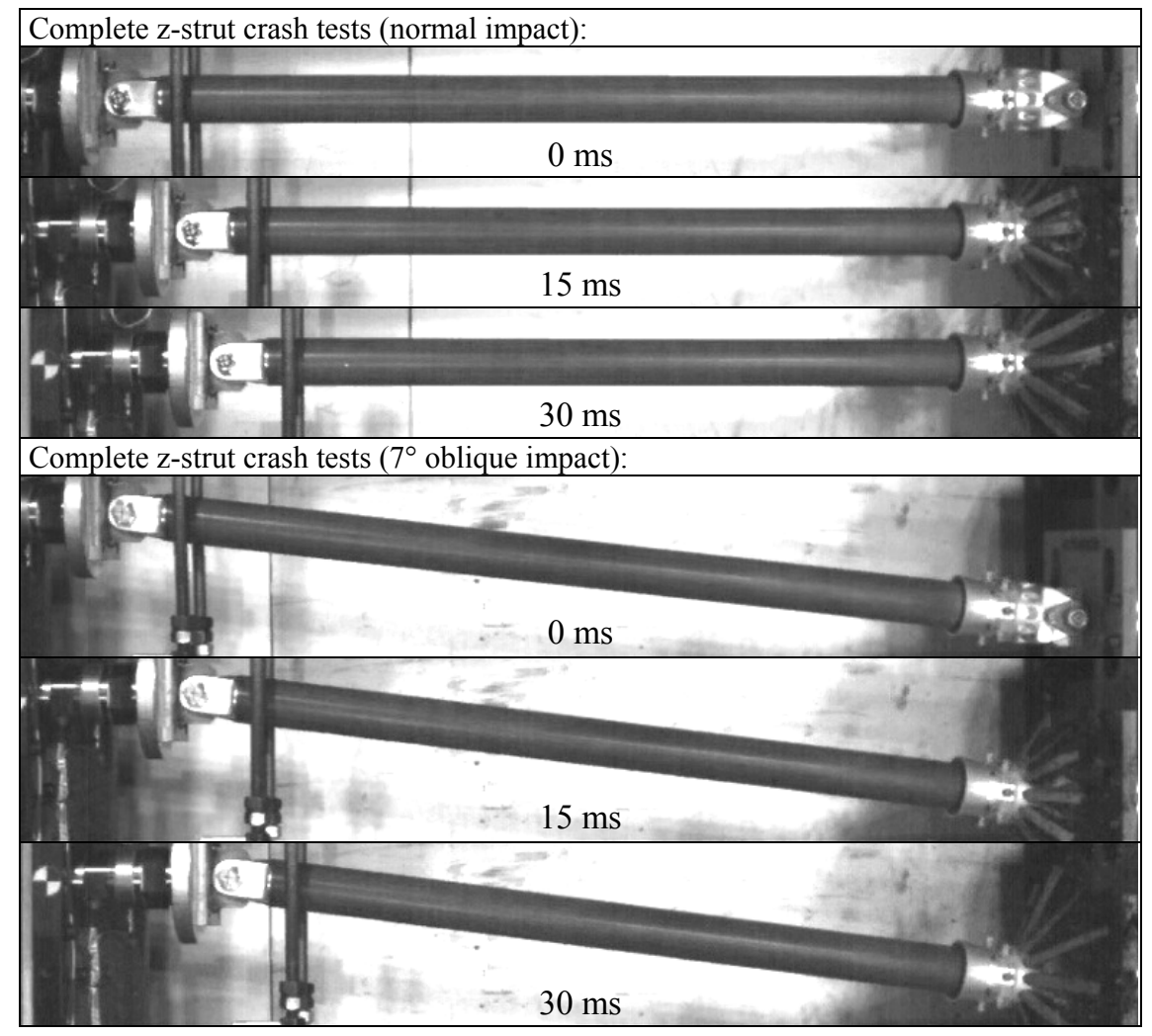

Figure 7: Extract of crash absorber test spectrum: complete z-strut tests.

\section{Physics of fragmentation}

The desire of today's engineer is to be able to generate a model of the respective structure in order to achieve efficient and predictive numerical design, reducing expensive testing efforts. For this reason, numerical analyses were also performed in the framework of the development of the crash absorber. However, since the failure behaviour is very complex, a fundamental understanding of the physical process of the composite crushing phenomena is mandatory before any model assumptions are made. Besides in-plane failure under bending, two degradation modes are dominating in this energy absorption process: fragmentation and delamination [20].

In this context, fragmentation can be seen as the last step of degradation, where the material is reduced to small particles. The initiation of fragmentation takes place at the microscale, where microscopic buckling of fibres occurs due to initial misalignments and fibre waviness, leading to kink band generation (Fig. 8, [21]).

The matrix material is supposed to support the fibres against microbuckling, but as soon as its yield strength is reached, fibre bending increases sharply and 


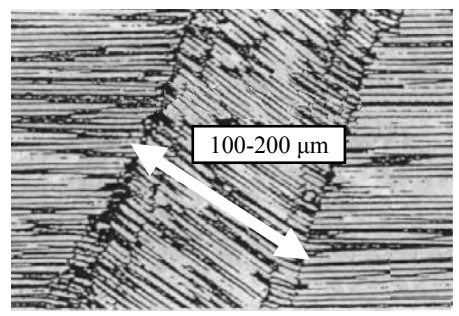

Figure 8: $\quad$ Microscopic observation of kink band [21].

stiffness drops with kink bands appearing that finally lead to catastrophic failure. An understanding of the energy dissipated in this process and influencing parameters was gained in [22] using a microscale modelling approach. To cover this energy absorption mechanism and also the fragmentation/delamination interaction in a meso- or macromodel for explicit finite element (FE) calculations typically used in industry today is still challenging and currently under investigations. Therefore, for first quantitative numerical evaluations, simplified phenomenological approaches were developed, e.g. either based on the definition of the mean crushing stress level of an element (CZone in ABAQUS [23]) or the reduction of the material strength in the vicinity of failed elements in order to generate stable crushing (crashfront algorithm in LS-DYNA [24, 25]). Indeed, the challenge remains to predict crush damage modes, its transitions and absorbed energy in mesoscale simulations based on regular material data.

Besides ply fragmentation, delamination as the interlaminar separation of two plies of the composite laminate is also a key mechanism in energy absorption. Since ply stiffness depends on the fibre orientation, adjacent layers with different fibre angles have different stiffnesses, leading to stress discontinuities and hence interlaminar shear stresses between the plies. In addition, the shearing crack propagation (mode II), which is most relevant for this absorber concept, was shown to be rate-dependent in [26]. Delamination modelling on the mesoscale typically involves interface models between separate plies or sublaminates represented with shell, continuum shell or solid elements. These interface models may e.g. be contact definitions or cohesive elements, with their failure behaviour classically being based on the cohesive zone model with a defined tractionseparation law.

\section{Modelling and simulation}

On this basis, it was investigated if the features available in today's commercial explicit FE codes are able and accurate enough to predict the crush load level of the z-strut absorber. Explicit codes have to be used because of the highly nonlinear behaviour in combination with the very short duration of the problem. In some recent papers similar crushing and delamination phenomena were investigated numerically using ABAQUS/explicit, with composite shell elements separated by cohesive elements for delamination [27-29]. In this study, the three commercial codes ABAQUS/explicit, LS-DYNA and PAM-CRASH were used. 
At first, the focus is on the ABAQUS/explicit model (Fig. 9). All aluminium parts, i.e. the absorber device, the inner ring and the support on the other side of the strut were modelled with C3D6 and C3D8R solid elements and an elasticplastic material law with isotropic hardening. The composite strut was modelled with two layers of S4R shell elements and one interface layer of $\mathrm{COH} 3 \mathrm{D} 8$ cohesive elements in-between for interlaminar separation (delamination). Intralaminar failure in the multi-layered composite shell elements is covered by the Hashin criteria [30] for damage initiation and a fracture energy-based formulation for damage evolution. The first row of elements in the strut was weakened to act as a trigger and initiate stable contact behaviour and crushing. It has to be mentioned that the cutting seams in the composite tube had to be predefined in the model like in [28] by lines of cohesive elements in order to achieve stable simulations and crack propagation. Although the shear pins were included in some first calculations on component level, they were excluded in the final crash simulation of the complete z-strut because the high loading rate in the crash test in combination with the limited sampling frequency and superimposed oscillations led to the fact that the shear pin failure could not be evaluated in the experimental force plots and therefore no comparison with the simulation was possible. A general contact definition was used to avoid penetration of the individual parts.

The boundary conditions were defined corresponding to the experimental crash tests with an impact velocity of $6.8 \mathrm{~m} / \mathrm{s}$ and an initial kinetic energy of $1911 \mathrm{~J}$.

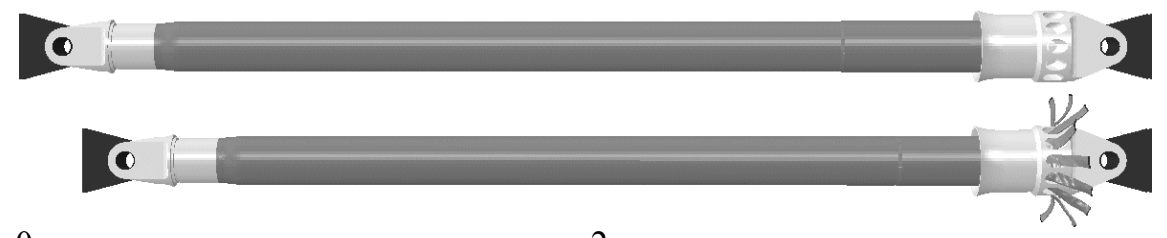

$0 \mathrm{~ms}$ :

$2 \mathrm{~ms}:$

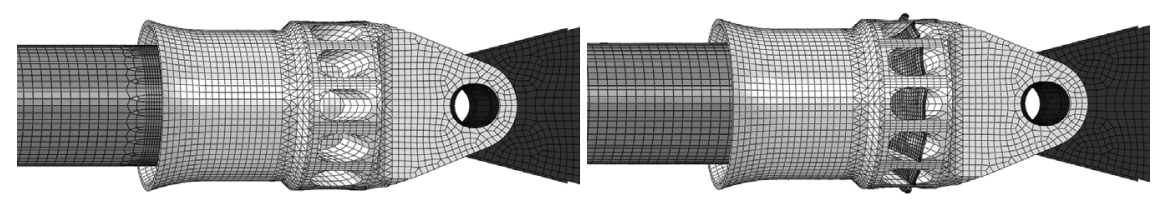

$4 \mathrm{~ms}: \quad 6 \mathrm{~ms}$ :

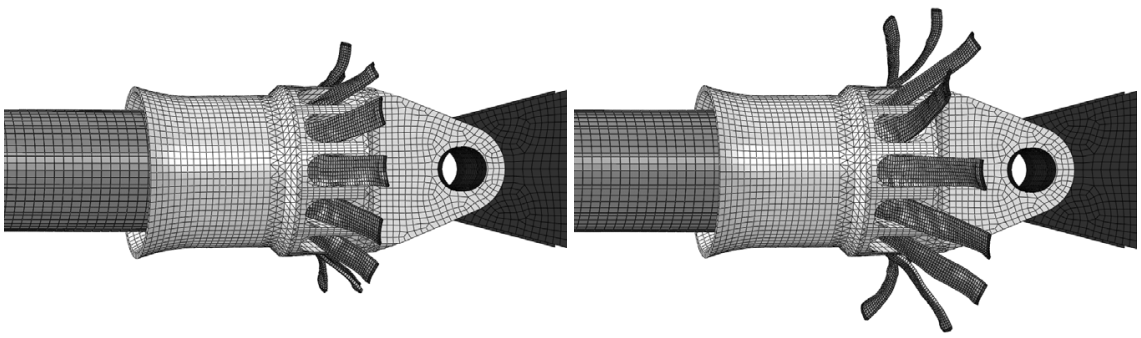

Figure 9: $\quad$ FE model for simulation of z-strut crushing. 
The force-displacement diagrams of crash test and ABAQUS/explicit simulation are shown in Fig. 10, both being recorded with the same frequency and filtered with an SAE600 filter. The simulation was stopped earlier after the stable crushing load level was clearly identified to save computational time. It can be seen that the load peaks in the beginning cannot be covered by this model, as they are the result of the crack initiation. The initiation, however, is predefined in the model by the cohesive interface seams, the simulation only covers failure propagation. It can be seen that the experimental curve is slightly progressive in the crushing zone, which is a result of wear at the cutting edges. This effect is not covered by the model. Although stress concentrations are visible in Fig. 11, the yield stress of the elements is not reached. The metallic cutting edges would have had to be modelled with a very fine mesh for this purpose, making the explicit calculation inefficient. However, besides these drawbacks, the most important characteristic - the crush load level - can be predicted quite satisfactorily. This is due to the fact that the main contributors to the energy absorption are represented in this model, the cutting of the tube into stripes by the cohesive elements and the damage and delamination modes under bending. Again, it has to be recalled that the real physical process of fragmentation cannot be represented by this mesomodel, it is just approximated. The robustness of the z-strut absorber against oblique loading conditions could also be shown successfully with this model.

Similar models were developed in the codes LS-DYNA and PAM-CRASH, to a large extent based on the same modelling methods and material parameters (LS-DYNA: MAT24 for aluminium, MAT54 for composite laminate, cohesive zone tiebreak contact for delamination, spotweld beams for the cutting seams, surface-to-surface contact; PAM-CRASH: material type 1 for aluminium, bi-phase material type 131 for composite laminate, tied interface type 303 for delamination and cutting seams, contact types 33 and 34). The results, although not shown here in further detail, were very similar, both qualitatively and quantitatively.

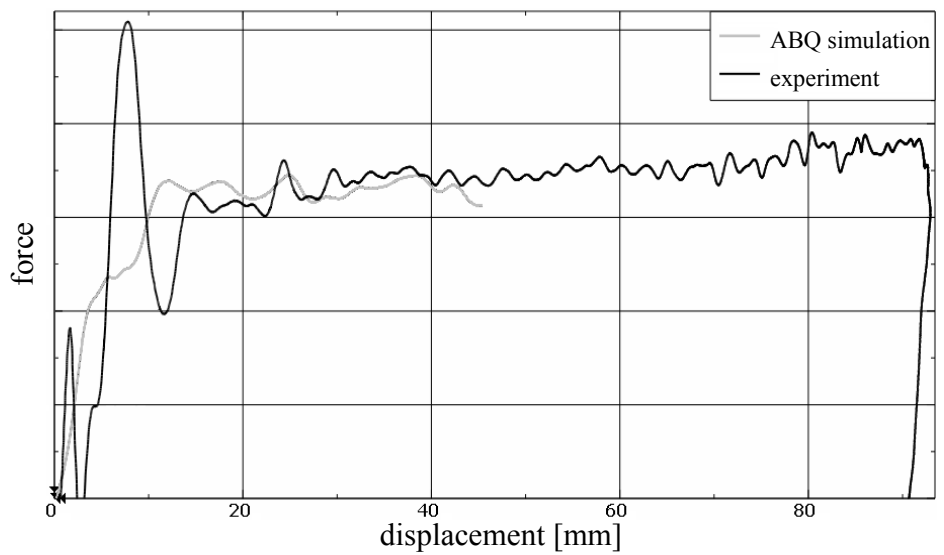

Figure 10: Crushing force vs. displacement diagram of complete z-strut, normal impact $1911 \mathrm{~J}$. 

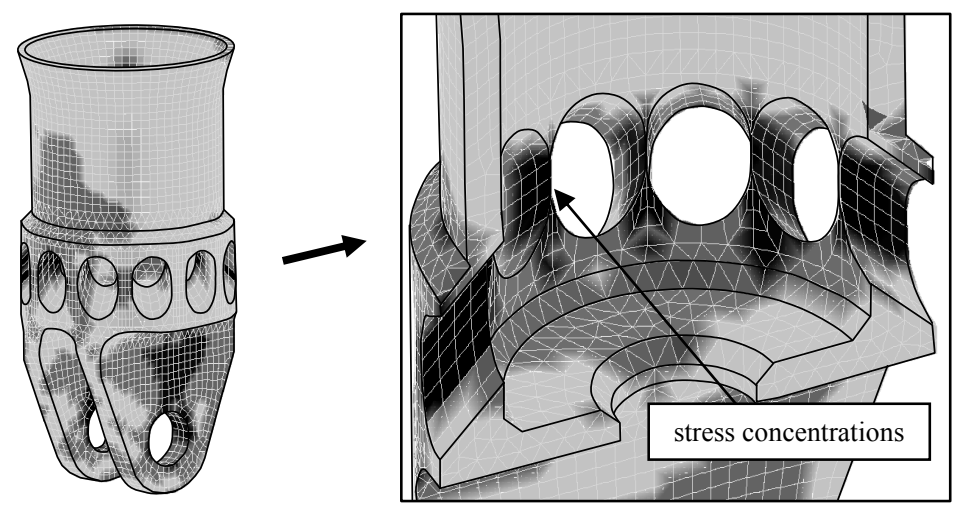

Figure 11: Von Mises stress concentrations at metallic absorber device cutting holes (no plasticity).

\section{Conclusions}

A lightweight composite crash absorber was developed, which can be used in the z-struts of a commercial aircraft to improve the crashworthiness behaviour. Component tests and complete z-strut crash tests under normal and oblique loading conditions provided consistent results within all requirements and showed a very high degree of robustness and reproducibility of the results. Although the absorber in this study was designed for specific load requirements, it can be adjusted to individual trigger and crush load levels by an appropriate choice of

- composite tube material, lay-up and thickness,

- shear pin material and design,

- angle of the deflection device,

- $\quad$ and number of cutting holes.

The use of explicit FE simulations with commercial codes for an overall prediction of the crush load level using mesomodels was shown to be successful to a certain extent. However, specific peaks in the load curve could not be represented, this would make a much more detailed and at the same time less efficient modelling approach necessary. The real physical fragmentation phenomena can also just be approximated, highlighting that the numerical prediction of composite energy absorption for industrial use cases is still a big challenge and currently under further investigations.

\section{References}

[1] Jackson, K.E.; Boitnott, R.L.; Fasanella, E.L.; Jones, L.E.; Lyle, K.H.: A history of full-scale aircraft and rotorcraft crash testing and simulation at NASA Langley Research Center. 4th Triennial International Fire \& Cabin Safety Research Conference, Lisbon, Portugal, 2004.

[2] Rassaian, M.; Byar, A.; Ko, J.: Numerical simulation of 737 fuselage section drop test. NAFEMS World Congress, Crete, Greece, 2009. 
[3] Hashemi, S.M.R.; Walton, A.C.: A systematic approach to aircraft crashworthiness and impact surface material models. Journal of Aerospace Engineering, 214(5), pp. 265-280, 2000.

[4] Kindervater, C.M.; Georgi, H.: Composite strength and energy absorption as an aspect of structural crash resistance. In: Structural Crashworthiness and Failure, N. Jones, T. Wierzbicki (eds.), Elsevier, pp. 189-235, 1993.

[5] Kindervater, C.M.; Kohlgrüber, D.; Johnson, A.: Composite vehicle structural crashworthiness - A status of design methodology and numerical simulation techniques. Int. J. of Crashworthiness, 4(2), pp. 213-230, 1999.

[6] Mahé, M.; Ribet, H.; Le Page, F.: Composite fuselage crash FE modelling dedicated to enhance the design in correlation with full scale drop test. Mécanique \& Industries, 2(1), pp. 5-17, 2001.

[7] Wiggenraad, J.F.M.; Michielsen, A.L.P.J.; Santoro, D.; Le Page, F.; Kindervater, C.; Beltran, F.; Al-Khalil, M.: Finite element methodologies development to simulate the behaviour of composite fuselage structure and correlation with drop test. Air \& Space Europe, 3(3-4), pp. 228-233, 2001.

[8] Kindervater, C.M.: The crashworthiness of composite aerospace structures. Workshop 'The Crashworthiness of Composite Transportation Structures', TRL, Crowthorne, UK, 2002.

[9] Arnaudeau, F.; Deletombe, E.; Mahé, M.; Le Page, F.: Crashworthiness of aircraft composites structures. ASME International Mechanical Engineering Congress \& Exposition (IMECE2002), New Orleans, LA, 2002.

[10] Fasanella, E.L.; Jackson, K.E.; Sparks, C.E.; Sareen, A.K.: Water impact test and simulation of a composite energy absorbing fuselage section. American Helicopter Society 59th Annual Forum, Phoenix, AZ, 2003.

[11] Meng, F.X.; Zhou, Q.; Yang, J.L.: Improvement of crashworthiness behaviour for simplified structural models of aircraft fuselage. International Journal of Crashworthiness, 14(1), pp. 83-97, 2009.

[12] Fasanella, E.L.; Jackson, K.E.; Kellas, S.: Soft soil impact testing and simulation of aerospace structures. 10th International LS-DYNA Users Conference, Dearborn, MI, 2008.

[13] Filsinger, J.; Middendorf, P.; Gessler, A.: Crash energy absorber element, connecting element with a crash energy absorber element of said type, and aircraft. Patent PCT/EP2007/062825, 2007.

[14] Farley, G.L.: Energy absorption of composite materials. Journal of Composite Materials, 17(3), pp. 267-279, 1983.

[15] Farley, G.L.; Jones, R.M.: Crushing characteristics of continuous fiberreinforced composite tubes. Journal of Composite Materials, 26(1), pp. 37 50, 1992.

[16] Brachos, V.; Douglas, C.D.: Energy absorption characteristics of hybrid composite structures. 27th International SAMPE Technical Conference, Albuquerque, NM, pp. 421-435, 1995.

[17] Mamalis, A.G.; Robinson, M.; Manolakos, D.E.; Demosthenous, G.A.; Ioannidis, M.B.; Carruthers, J.J.: Crashworthy capability of composite material structures. Composite Structures, 37(2), pp. 109-134, 1997. 
[18] Pein, M.; Krause, D.; Heimbs, S.; Middendorf, P.: Innovative energyabsorbing concept for aircraft cabin interior. International Workshop on Aircraft System Technologies (AST2007), Hamburg, Germany, 375-384, 2007.

[19] Garner; D.M.; Adams, D.: Test methods for composites crashworthiness: A review. Journal of Advanced Materials, 40(4), pp. 5-26, 2008.

[20] Guimard, J.M.; Allix, O.; Pechnik, N.; Thevenet, P.: Energetic analysis of fragmentation mechanisms and dynamic delamination modelling in CFRP composites. Computers \& Structures, 87(15-16), pp. 1022-1032, 2009.

[21] Effendi, R.R.; Barrau, J.; Guedra-Degeorges, D.: Failure mechanism analysis under compression loading of unidirectional carbon/epoxy composites using micromechanical modelling. Composite Structures, 31(2), pp. 87-98, 1995.

[22] Guimard, J.M.; Allix, O.; Pechnik, N.; Thevenet, P.: Statistical energy and failure analysis of CFRP compression behavior using a uniaxial microbuckling model. Journal of Composite Materials, 41(23), pp. 28072828, 2007.

[23] Indermuehle, K.; Barnes, G.; Nixon, S.; Schrank, M.: Simulating composites crush and crash events using ABAQUS. 50th AIAA/ASME/ASCE/AHS/ASC Structures, Structural Dynamics, and Materials Conf., Palm Springs, 2009.

[24] Rassaian, M.; Byar, A.; Bolukbasi, A.; Feraboli, P.; Deleo, F.: Crashworthiness of composite structures: Numerical and experimental guidelines. NAFEMS World Congress, Crete, Greece, 2009.

[25] Heimbs, S.; Strobl, F.; Middendorf, P.; Gardner, S.; Eddington, B.; Key, J.: Crash simulation of an F1 racing car front impact structure. 7th European LS-DYNA Users Conference, Salzburg, Austria, 2009.

[26] Guimard, J.M.; Allix, O.; Pechnik, N.; Thevenet, P.: Chracterization and modelling of rate effects in the dynamic propagation of mode-II delamination in composite laminates. Int. J. of Fracture, 160(1), pp. 55-71, 2009.

[27] Guillon, D.; Rivallant, S.; Barrau, J.J.; Petiot, C.; Thevenet, P.; Malherbe, B.: Experimental and numerical study of the splaying mode crush of CFRP laminates. 17th Int. Conference on Composite Materials (ICCM-17), Edinburgh, UK, 2009.

[28] Palanivelu, S.; Van Paepegem, W.; Degrieck, J.; Kakogiannis, D.; Van Ackeren, J.; Van Hemelrijck, D.; Wastiels, J.: Numerical energy absorption study of composite tubes for axial impact loadings. 17th International Conference on Composite Materials (ICCM-17), Edinburgh, UK, 2009.

[29] Swaminathan, N.; Averill, R.C.: Contribution of failure mechanisms to crush energy absorption in a composite tube. Mechanics of Advanced Materials and Structures, 13(1), pp. 51-59, 2006.

[30] Hashin, Z.: Failure criteria for unidirectional fiber composites. Journal of Applied Mechanics, 47(2), pp. 329-334, 1980. 